\title{
EI derecho a la vida como derecho a nacer
}

\author{
Miguel Ángel Alegre Martínez \\ Profesor Titular de Derecho Constitucional \\ Universidad de León
}

Recibido: 02.05.12

Aceptado: 31.05 .12

Resumen: Se hace una consideración en relación al derecho a la vida y a la dignidad humana desde la perspectiva española y europea. Se pone en relevancia deber de respetar la vida ajena y, por tanto, de no lesionarla, de no causar por ningún medio ni procedimiento su final.

Palabras clave: Dignidad humana, derecho a la vida, Derechos Humanos, Tribunal Constitucional, Tribunal Europeo de Derechos Humanos

Abstract: In this paper there is a consideration regarding the right to life and human dignity from the Spanish and European perspective. Is pointed out the importance of the respect for lives.

Key words: Human dignity, right to life, Human Rights, Constitutional Court, European Court of Human Rights.

La reciente lectura de varios excelentes artículos, testimonios y otros materiales, me ha animado a exponer e intentar explicar, una vez más, mi postura favorable al derecho a la vida del no nacido, como consecuencia y proyección de la dignidad humana y el libre desarrollo de la personalidad (artículo 10.1 de la Constitución española) y el derecho de todos a la vida (artículo $15 \mathrm{CE})^{1}$.

${ }^{1}$ ALEGRE MARTÍNEZ, Miguel Ángel, La dignidad de la persona como fundamento del ordenamiento constitucional español, Secretariado de Publicaciones de la Universidad de León, 1996; “Apuntes sobre el derecho a la vida en España: Constitución, jurisprudencia y realidad", Revista de Derecho Político, n 53, Madrid, UNED, 2002, págs. 337-358; Recensión al libro La Constitución día a día de Joan Oliver Araujo |Valencia, Tirant lo Blanch, "Alternativa", 2003], Cuadernos Constitucionales de la Cátedra Fadrique Furió Ceriol, $\mathrm{n}^{\circ}$ 47, Universidad de Valencia, 2004, págs. 165-174; "El reconocimiento constitucional de la dignidad humana: significado y alcance", en José Peña González (Coord.), Libro Homenaje a D. Iñigo Cavero Lataillade, Universidad San Pablo-CEU, Ed. Tirant lo Blanch, Valencia, 2005, págs. 55-70; "Reconocimiento constitucional de la dignidad, individualidad y derechos de la personalidad" (con Óscar Mago Bendahán), Revista de Derecho Político, $\mathrm{n}^{\circ}$ 66, Madrid, UNED, 2006, págs. 183-234; Derechos de la personalidad y derecho de los daños morales (con Óscar Mago Bendahán), Caracas, Constitución Activa ("Breviarios del nuevo Derecho"), 2007; "El aborto es incompatible con la Constitución", en el Foro de CiViCa, Asociación de Investigadores y Profesionales por la Vida, http://www.investigadoresyprofesionales.org/ http://cienciavculturaporlavida.blogspot.com/2009/11/elaborto-es-incompatible-con-la.html (21 de noviembre de 2009); "El derecho constitucional 
Me refiero a textos como: "Más reformas en Justicia y sus alternativas (IV)" (de Joaquín BRAGE CAMAZANO²); "Aborto antes del parto... ¿Y después?" (de José Manuel BELMONTE3); “Aborto, verdad y bioética" (de César NOMBELA $\left.{ }^{4}\right)$; " $i S e$ puede considerar el aborto post-parto un infanticidio?" (de Nicolás JOUVE5); "Mi compromiso con la vida" (de Sebastián PIÑERA ${ }^{6}$ ); "Más allá del aborto actual... ¿El infanticidio legal? (de Carmen GONZALEZ MARSAL7); así como al "Manifiesto 25 de marzo, por una investigación biomédica eficiente, respetuosa con el ser humano y adecuada a la legislación europea"

Aunque siempre es buen momento para retomar el tema de la fundamentación del derecho a la vida, considero que el delirante artículo de los expertos en Bioética Alberto Giubilini y Francesca Minerva en el que se considera moralmente equivalente al aborto (y, por tanto, admisible según ellos) matar a los recién nacidos, nos ofrece una ocasión particularmente favorable para realizar algunas consideraciones que, no por obvias, dejan de suscitar polémica y generar rechazo por parte de tantos adalides de lo políticamente correcto. El controvertido trabajo, publicado en la revista británica Journal of Medical Ethics el 22 de febrero de 2012 ha sido objeto de comentario en algunos de los artículos citados. Por eso intentaremos aquí plantear la cuestión desde una perspectiva más general, no sin lamentar con perplejidad que el pensamiento científico se haya alejado del sentido común hasta el punto de que, en tiempos como los actuales y en sociedades supuestamente evolucionadas y avanzadas, haga falta explicar que es el aborto lo conceptualmente equiparable al infanticidio, y no al revés.

I. Situándonos inicialmente en el contexto español: La Constitución, lejos de dejar abierto el tema de la titularidad del derecho a la vida, lo resuelve afirmando este derecho respecto de "todos" (artículo $15 \mathrm{CE}$ ), lo cual ha de ponerse en conexión con el artículo 10.1, que proclama el "libre desarrollo de la personalidad" como consecuencia y proyección de la dignidad de la persona: es decir, de todo ser humano, no solo de los nacidos.

Sin embargo, el Tribunal Constitucional ha negado al nasciturus (concebido y no nacido) la titularidad del derecho a la vida, a partir de la STC

al servicio de la persona: la protección a los más vulnerables y los nuevos derechos", publicado en el Archivo Digital BULERIA (Biblioteca Universitaria de León. Repositorio Institucional Abierto): https://buleria.unileon.es/handle/10612/503 . Identificador: http://hdl.handle.net/10612/503 Octubre 2010.

${ }^{2}$ http://www.elheraldodelhenares.es/pag/noticia.php? cual $=12850$

${ }^{3}$ http://www.elheraldodelhenares.es/pag/noticia.php? cual $=12454$

${ }^{4}$ http://www.abc.es/historico-opinion/index.asp?ff $=20120314 \& i d n=1502533715585$

${ }^{5} \mathrm{http}: / / w w w$.investigadoresyprofesionales.org/drupal/content/\%C2\%BFse-puede-considerar-el-aborto-post-parto-un-infanticidio

${ }^{6} \mathrm{http}: / / w w w$.diarioya.es/content/mi-compromiso-con-la-vida-por-sebasti\%C3\%Alnpi\%C3\%Blera-presidente-de-chile

${ }^{7}$ http://www.medicinayhumanidades.cl/ediciones/n12010/05_Mas_alla_aborto.pdf

${ }^{8}$ http://www.profesionalesetica.org/manifiesto.php 
53/1985 de 11 de abril, reiterando esta postura en las SSTC 212/1996 de 19 de diciembre (Fundamento Jurídico 3) y 116/1999 de 17 de junio. Con ello, el Tribunal Constitucional ha provocado una auténtica mutación (o modificación no formal de la Constitución) al interpretar que ésta dice justamente lo contrario de lo que dice (a pesar de reconocer que, con la inclusión del término "todos", se pretendió lograr la plena y eficaz protección del nasciturus, según consta en los propios debates constituyentes). Esto se debe fundamentalmente a que el Tribunal Constitucional se acoge al concepto de "persona" que, para el ámbito de las relaciones jurídicas privadas, contiene el Código Civil (el cual establece en su artículo 29 que el nacimiento determina la personalidad), en lugar de aprovechar los ya mencionados elementos que la Constitución ofrece para extraer un concepto lo más amplio y favorable posible de persona. Olvida además el Tribunal Constitucional que, según el mismo artículo del Código Civil, "el concebido se tiene por nacido para todos los efectos que le sean favorables". El Tribunal Constitucional (al que se supone el máximo garante de la Constitución) ha dejado así desprotegido el derecho a la vida, abriendo la puerta a la legislación despenalizadora del aborto, negando el derecho a nacer del nasciturus, y negándole, por tanto, todos los demás derechos constitucionalmente reconocidos. Con ello ha socavado el fundamento mismo sobre el que se asienta todo el sistema diseñado en nuestra vigente Constitución?

${ }^{9}$ La actual regulación de la llamada "interrupción" voluntaria del embarazo se halla contenida en la Ley orgánica $2 / 2010$ de 3 de marzo, de salud sexual y reproductiva y de la interrupción voluntaria del embarazo (BOE de 4 de marzo). Esta Ley orgánica entró en vigor el 5 de julio de 2010, después de que el Tribunal Constitucional rechazara la suspensión cautelar de la vigencia de la ley, solicitada por los firmantes del recurso de inconstitucionalidad contra la misma (Auto TC de 14 de julio de 2010), a pesar de que los efectos de la aplicación de la ley son obviamente irreversibles, y las vidas eliminadas bajo la cobertura de esta norma no se podrán recuperar si en su momento es declarada inconstitucional, como se hace constar en los votos particulares al mismo.

Puede consultarse su texto en: http://www.boe.es/boe/dias/2010/03/04/pdfs/BOE-A2010-3514.pdf

La mencionada ley orgánica ha sido desarrollada por los Reales Decretos 825/2010 y $831 / 2010$, ambos de 25 de junio, publicados en el BOE de 26 de junio.

http://www.boe.es/boe/dias/2010/06/26/pdfs/BOE-A-2010-10153.pdf

http://www.boe.es/boe/dias/2010/06/26/pdfs/BOE-A-2010-10154.pdf

El primero de ellos acomete el "desarrollo parcial" de la ley orgánica, mientras que el segundo se ocupa de la "garantía de la calidad asistencial de la prestación a la interrupción voluntaria del embarazo". Véanse, entre otros muchos comentarios, el de José MAZUELOS, "La lógica inhumana de la Ley del Aborto", así como otras noticias y comentarios relacionados: "El Tribunal Constitucional rechaza suspender con urgencia la Ley del Aborto", http://www.forumlibertas.com/frontend/forumlibertas/noticia.php?id_noticia= $17580 \& i d \_s e c c i o n=24 \&$ PHPSESSID $=e 4 f 9044646 b 0$ e6dce856bbd8ccle2032 ; y "Aborto: una ley abiertamente inconstitucional", http://www.libertaddigital.com/opinion/editorial laborto-una-ley-abiertamente-inconstitucional-55594/ 
Desde mi punto de vista, la lectura de los artículos 10.1 y 15 de la Constitución (sin olvidar tampoco el 39) hace jurídicamente imposible seguir considerando vigentes los preceptos del Código Civil según los cuales la personalidad viene determinada por el nacimiento (art. 29) y se extingue [especificando aquí "la personalidad civil"] por la muerte de la persona (art. 32). El desfasado concepto de persona que ofrece el Código Civil, diseñado fundamentalmente para regular la seguridad del tráfico jurídico, debe considerarse no sólo superado, sino derogado en virtud del punto tercero de la Disposición derogatoria de la Constitución. En efecto, aparte del "Todos" utilizado por el artículo 15 para referirse a los titulares del derecho a la vida, el artículo 10.1 vincula la dignidad humana con el "libre desarrollo de la personalidad". La personalidad puede desarrollarse en cuanto que existe; y no podrá desarrollarse si se elimina al sujeto en cualquier momento de la gestación.

No creo que exista razón que justifique la diferencia (incompatible por lo demás con el artículo $14 \mathrm{CE}$ ) entre nacidos y no nacidos que el Código Civil establece inicialmente, y que después trata de reparar mediante una especie de "discriminación positiva" del artículo 29 que neutralice la anterior discriminación sin paliativos.

En todo caso, la persona es algo más que un ser dotado de personalidad civil, y ni siquiera los Magistrados del Tribunal Constitucional son quiénes para negarle los derechos vinculados a su condición de ser humano. A estos efectos, interesará recordar que el artículo 6 de la Declaración Universal de los Derechos Humanos de 1948 (que, según el art. 10.2 de la Constitución española, sirve como criterio privilegiado de interpretación en esta materia) determina que "Todo ser humano tiene derecho, en todas partes, al reconocimiento de su personalidad jurídica". Ello significa que todo ser humano es titular de los derechos que la Constitución reconoce, lo cual se aprecia claramente en relación con el derecho a la vida: la lesión del mismo (quitar la vida a un ser humano) no sólo es irreversible, sino que obviamente le impide ejercer y disfrutar cualquier otro derecho: si no se respeta el derecho a la vida, da igual todo lo demás. Por poner un ejemplo gráfico: ¿De qué sirven todas las medidas para evitar o frenar el cambio climático, o las que se pudieran tomar para proteger el medio ambiente como establece el artículo 45? ¿De qué sirve el derecho a respirar aire sano, si a más de cien mil seres humanos al año en España no se les reconoce siquiera el derecho a respirar? El mismo razonamiento valdría para la libertad de información, el derecho a la salud, o cualquier otro.

Seguramente ese es el motivo por el que la misma Declaración Universal determina, desde su primer artículo, que "Todos los seres humanos nacen libres e iguales en dignidad y derechos", afirmando así que antes de nacer ya son seres humanos. Entiendo que esta interpretación (que, en el contexto constitucional español encuentra apoyo en el tenor literal de los artículos 10.1 y 15 , utilizando éste último la expresión "Todos") es la única coherente con el principio de universalidad de los derechos. También en consonancia con la postura que mantenemos se encuentran los artículo 3 y 6 de la misma Decla- 
ración Universal, a cuyo tenor "Todo individuo tiene derecho a la vida, a la libertad y a la seguridad de su persona", y "Todo ser humano tiene derecho, en todas partes, al reconocimiento de su personalidad jurídica".

También como argumento en el orden internacional podríamos tener en cuenta el Estatuto de Roma de la Corte del Tribunal Penal Internacional, de 1998. No descarto, por ejemplo, que la eufemísticamente llamada "interrupción voluntaria del embarazo" (no tiene nada de "interrupción", pues implica la eliminación definitiva del nasciturus), encaje en el supuesto de "genocidio" contemplado en el artículo 6 de dicho texto: "Matanza de miembros del grupo" [valdría decir, niños no nacidos], "Medidas destinadas a impedir nacimientos en el seno del grupo"... En todo caso, creo que la interrupción voluntaria del embarazo encajaría también en los supuestos que enumera el artículo 7 del citado Estatuto: "Ataque generalizado o sistemático contra una población civil...", "exterminio", "desaparición forzada de personas", etc.

Pero, incluso, aunque alguien pudiera decir que resultaría forzada la inclusión del aborto dentro de estos delitos, creo que por sí mismo, sin necesidad de encajarlo en ningún otro tipo, se trata de una violación grave de derechos humanos. No sólo por ser masiva (no todo lo grave es masivo, pero todo lo masivo sí es grave, aunque uno solo ya lo es); sino también por ser una práctica reiterada y persistente... e incluso por su dimensión transnacional: casi cinco mil portuguesas vienen cada año al paraíso abortista en que -como todo el mundo sabe- se ha convertido España (sin perjuicio de que Portugal haya abierto la puerta a una regulación más permisiva en la materia tras el referéndum de febrero y la posterior reforma legislativa de abril de 2007). Cada treinta segundos se practica un aborto en la Unión Europea, y sólo en España se superaron en 2010 los 113.000 abortos anuales bajo la cobertura de la legislación despenalizadora, y la lamentable doctrina del Tribunal Constitucional a la que más arriba me he referido. Es decir, aproximadamente, cada cinco minutos se elimina legalmente a un ser humano en España. Hay provincias españolas que no tienen tanta población: es, pues, algo así, como barrer cada año un número de vidas humanas superior a la población de muchas provincias. A nivel mundial, se habla de unos 1500 millones de seres humanos eliminados antes de nacer; teniendo en cuenta que el mundo tiene unos 6700 millones de habitantes, se concluye que en unos cuarenta años se ha eliminado a una cuarta parte de la Humanidad. Al contemplar esta hecatombe humanitaria y esta barbarie moral, ¿Qué escribirán los historiadores del futuro sobre esta "civilización" en la que países -como el nuestro- que se dicen respetuosos con los derechos humanos legislan pisoteando el más básico de ellos? ¿Cómo explicar la contradicción en la que incurren los que se llenan la boca con los derechos humanos y se tapan los ojos y los oídos ante esta situación?

De hecho, considero que la interrupción voluntaria de la gestación conlleva un deterioro irreparable para un sistema político democrático al suponer la eliminación sistemática de vidas humanas. Y todo ello envuelto en la falacia, que ya es hora de desmontar, consistente en asociar el aborto a la idea de 
"progresismo". El progresismo, al buscar la protección del más débil, no puede consistir en la eliminación de la vida del no nacido, por mucho que la presentemos como algo neutro y cotidiano. Considerar que determinadas vidas no merecen la pena ser vividas, o que determinados embarazos son un error, sí que está lleno de prejuicios que un espíritu progresista no debería aceptar.

No es difícil intuir la presión que ejercieron las corrientes de opinión que llevaron al anterior Gobierno y al partido que lo sustentaba a plantear el paso adelante en materia de aborto. Supongo que si lo han planteado será porque creían que podía ser rentable en términos electorales. También soy consciente de los importantes intereses económicos en juego; asímismo me llama la atención lo absurdo de los argumentos que se dieron para profundizar en la despenalización del aborto (vendría a ser algo así como que, dado que se estaban cometiendo irregularidades bajo la anterior ley, procedía cambiarla para que cupiera en ella lo que antes eradelito). Me gustaría suponer que el Tribunal Constitucional declarará inconstitucional la actual legislación sobre el aborto, aunque poco cabe esperar, después de que este supuesto garante de la Constitución haya abierto la puerta, con su doctrina, a la anterior legislación, ya de por sí inconstitucional a todas luces como he intentado explicar más arriba. Soy, como digo, consciente de todo ello. Pero, por todo lo expuesto, también lo soy de que el aborto, tanto bajo la actual legislación como bajo cualquier otra ley despenalizadora, es incompatible con nuestro Texto constitucional.

II. Puesto que la problemática aquí tratada trasciendo los límites de un determinado país u ordenamiento jurídico, no estará de más realizar alguna consideración adicional. Si el Derecho (en concreto el Derecho Constitucional) está al servicio de la persona, tiene que estarlo de la vida humana; y sobre todo, deberá estar al servicio de las vidas humanas más vulnerables y del deber de respetarlas.

La dignidad de la persona no sólo existe allí donde el respectivo ordenamiento jurídico la reconoce, y en la medida en que la reconoce: la dignidad va unida a la propia naturaleza humana, es previa al Derecho, y por tanto, no sólo es lo que el Derecho dice que es. Lo mismo ocurre, lógicamente, con los derechos derivados de esa dignidad, y con la posible introducción o aceptación de nuevos derechos que lleguen de la mano de prácticas médicas o avances científicos. Supuestos "nuevos derechos" de los que continuamente oímos hablar (y que en los últimos tiempos encuentran acomodo en nuestro ordenamiento por vía legislativa) como a interrumpir el embarazo, a decidir sobre la propia muerte, a llevar a cabo técnicas reproductivas que conlleven la destrucción de embriones, etc., no son en realidad derechos, puesto que suponen la negación, la contradicción o la lesión de esos otros derechos que entroncan con la naturaleza humana y encuentran su fundamento en la dignidad. La salud y el avance científico, sirven de excusa en estos casos para hacer prevalecer otro tipo de corrientes ideológicas e intereses económicos que nada tienen que ver con el progreso, pues lesionan y menoscaban la vida humana en lugar de promocionarla y favorecerla. 
De este modo, como anticipábamos, lo que sucede es que la Constitución se deja de lado, queda marginada, dando paso a supuestos nuevos derechos que no sólo no están en ella, sino que contradicen, lesionan y pretenden ignorar a los constitucionalmente reconocidos. Esta realidad es, precisamente, la que nos da la clave para formular un criterio general: solo estaremos ante un verdadero nuevo derecho cuando su reconocimiento o su aplicación no contradiga, lesione o atente contra otros derechos humanos, en especial el derecho fundamental e inalienable a la vida. Si se pretende mejorar la vida, no será admisible lo que la destruya. El Estado puede reconocer derechos: no crearlos ni negarlos, ni hacerlos depender de las cambiantes mayorías parlamentarias o de las modas o corrientes de opinión presentes en la sociedad. Si no se tienen en cuenta este criterio, si aceptamos sin más (como meros e indiferentes espectadores) las modificaciones normativas y los avances científicos y técnicos prescindiendo en unas y otros de toda consideración ética, acabaremos asumiendo sin mayor reflexión que unas vidas merecen ser vividas y otras no, que unas personas pueden -e incluso deben- decidir sobre la vida o la muerte de otras, que la persona no es más que un conjunto de células, órganos, huesos y músculos, un objeto, un mero instrumento, un trozo de materia orgánica. Y entonces, el paso consistente en considerar "derechos" lo que antes eran "fenómenos" y "prácticas", será un irreversible salto en el vacío.

Así pues, resulta sencillo deducir el corolario que se desprende de la argumentación expuesta en estas páginas: el hilo que conduce al ovillo, tiene su origen y su meta en la necesaria protección del derecho a la vida (que se traduce en el deber de no atentar contra ella) como premisa ineludible para el respeto y disfrute de los demás derechos. El respeto de la dignidad humana y el de los derechos que de ella se derivan, sólo es compatible con el respeto a la vida, a la calidad de vida, a la esperanza de vida. El derecho a la vida es el soporte de todos los demás, "en cuanto que es el presupuesto ontológico sin el que los restantes derechos no tendrían existencia posible" (STC 53/1985 de 11 de abril). Ese derecho se traduce y concreta en el deber de respetar la vida ajena $\mathrm{y}$, por tanto, de no lesionarla, de no causar por ningún medio ni procedimiento su final.

Si el derecho a la vida del no nacido se hace depender de la voluntad de otras personas, que además podrán decidir sobre ella de forma libre e incondicional, estamos ante el más claro ejemplo de desprotección de una vida humana vulnerable.

Por eso, no sólo en el plano de la dignidad, sino en el de la igualdad, el respeto del derecho a la vida del no nacido (en definitiva, el derecho a nacer) encuentra adecuado fundamento. Mientras no se tenga claro que el derecho a nacer, como consecuencia lógica e inmediata del derecho a la vida, debe prevalecer sobre cualquier otro, ¿cómo será posible la igualdad? ¿Cabe discriminación más grave que poner fin a la gestación de esa vida humana (vulnerable y dependiente como ninguna otra) que es el nasciturus? La igualdad básica, la igualdad primera a partir de la cual pueden buscarse y cons- 
truirse las demás es la igualdad en el derecho a nacer. La igualdad "desde el nacimiento" pasa necesariamente por la igualdad "en el nacimiento", esto es: porque éste no dependa de la voluntad de otra(s) persona(s).

Insistimos: ¿Pueden jactarse España y tantos otros países de ser respetuosos con los derechos humanos? A quien no se le respeta el derecho a la vida, se le están negando todos los demás. Por este camino llegamos al horizonte de los "países sin Constitución", que se hace presente como una dramática realidad, al suponer la negación y renuncia a todos los logros obtenidos a lo largo de más de doscientos años. Al respecto, baste citar el artículo 16 de la Declaración francesa de los Derechos del Hombre y del Ciudadano de 1789, según el cual "Toda sociedad en la cual la garantía de los derechos no esté asegurada, ni la separación de poderes determinada, no tiene constitución".

A lo largo de todo este tiempo, la evolución de los derechos ha consistido en su aparición paulatina, escalonada: cada nueva "generación" supone la superación de la anterior; una evolución lineal, progresiva, siempre en el mismo sentido. Sin embargo, hoy observamos una evolución en dos sentidos opuestos: por un lado, el claro retroceso de los derechos básicos (al disminuir o desaparecer la protección debida a la vida humana); y, por otro, la aparición de nuevos derechos, que quizá vienen a disimular el retroceso de los más tradicionales, pero que ningún sentido tienen sin éstos. Esos nuevos derechos supondrían, entonces, una huída hacia adelante, mirar hacia otro lado. Esa evolución en dos sentidos opuestos recuerda la imagen gráfica de una cuerda o goma elástica de la que tiran dos fuerzas opuestas, y al final se puede romper. Quizá aún estemos a tiempo de darnos cuenta de que, en el ámbito jurídico el sentido no tiene por qué ser incompatible con la sensibilidad. 